\title{
Anaemia among mother-father-child pairs in India: examining co-existence of triple burden of anaemia in a family
}

\author{
Pradeep Kumar(D, Shekhar Chauhan(D, Ratna Patel[D and Shobhit Srivastava* (i)
}

\begin{abstract}
Background: Anaemia is a global health concern and is also a common comorbidity in multiple medical conditions. Very limited research is available examining anaemia among family members in India and across various countries. The present study aimed to examine the co-existence of the triple burden of anaemia among motherfather-child pairs in a family.

Methods: The data utilized was from the National Family Health Survey conducted in 2015-16. The effective sample size for the study was 26,910 couples, along with children aged 6-59 months. The bivariate and binary logistic regression analysis were applied to assess the factors associated with family-level anaemia. In bivariate analysis, a chisquare test was performed to determine the association of socio-demographic factors with anaemic family.

Results: More than half of the mothers (57.5\%) and their children (58\%), along with $10 \%$ of fathers, were found to be anaemic; however, the co-existence of triple burden of anaemia among mother-father-child pairs was $4.7 \%$ in the study. The likelihood of family-level anaemia was low when both the parents were educated [OR: 0.69, Cl: 0.58-0.81], and it was high when both the parents were employed [OR: 1.40 Cl: 1.10-1.80]. Families from the Scheduled Tribe had a $62 \%$ higher likelihood to suffer from anaemia [OR: 1.62, Cl: 1.33-1.97].

Conclusions: The suggested interventions include early diagnosis, effective management, and treatment of anaemia. Moreover, adequate complementary feeding practices for children shall also be promoted. Parental education on nutrition is also required, and community interventions are needed to improve parental education on nutrition. At last, there is a need for greater policy and program attention to improving nutritional knowledge among mothers so as to tackle the triple burden of anaemia among mother-father-child pairs.
\end{abstract}

Keywords: Anaemia, Triple burden, Family, India, National family health survey

\section{Background}

Anaemia is a global health concern and is also a common comorbidity in multiple medical conditions [1]. Anaemia is a condition that affects all age groups; however, it is more prevalent during the first two years of life, during adolescence and during pregnancy among women [2]. Around one-third (32.9\%) of the world's

* Correspondence: shobhitsrivastava889@gmail.com International Institute for Population Sciences, Mumbai, Maharashtra 400088, India

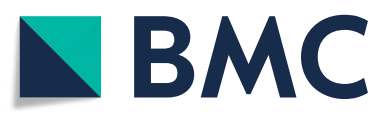

C C The Author(s). 2021 Open Access This article is licensed under a Creative Commons Attribution 4.0 International License, which permits use, sharing, adaptation, distribution and reproduction in any medium or format, as long as you give appropriate credit to the original author(s) and the source, provide a link to the Creative Commons licence, and indicate if changes were made. The images or other third party material in this article are included in the article's Creative Commons licence, unless indicated otherwise in a credit line to the material. If material is not included in the article's Creative Commons licence and your intended use is not permitted by statutory regulation or exceeds the permitted use, you will need to obtain permission directly from the copyright holder. To view a copy of this licence, visit http://creativecommons.org/licenses/by/4.0/. The Creative Commons Public Domain Dedication waiver (http://creativecommons.org/publicdomain/zero/1.0/) applies to the data made available in this article, unless otherwise stated in a credit line to the data. 
states of India noticed that around one-fourth of the men were suffering from anaemia [5]. In the current scenario, the situation has not improved much, and children and women continue to be highly affected by anaemia as compared to men [1].

Anaemia among children is a widely studied topic [68]. Various studies have noted specific determinants of anaemia among children. Household wealth and maternal anaemia were associated with anaemia among children [7]. Another study noted that maternal education plays a significant role in controlling anaemia among children [6]. Another study noted maternal education, residence, and wealth index correlate with childhood anaemia [9]. Similarly, various studies have also examined the correlates of anaemia among women [10, 11]. Household wealth index and place of residence were found to be significant determinants of anaemia among women [11]. Men have been mainly ignored in anaemiafocused research and policies [12]. The limited availability of literature on anaemia among men makes this study important in the current context. A study has found that the prevalence of anaemia among men has remained unchanged (23\%) in the last 10 years, from 2006 to 2016 [10]. The same study confirmed that higher levels of anaemia among men were found in those residing in rural areas, employed in more labour-intensive activities, and belonging to the lowest wealth quintile [12].

Anaemia among children in India has studied extensively [13]. Similarly, anaemia among women is one of the well-documented topics, and literature is available in abundance, examining factors associated with anaemia among women [14]. Anaemia has always been a topic of immense interest among researchers in India; however, nearly all the research on anaemia is attributed to either children or women $[15,16]$. Not only in India but also in other countries too, literature about anaemia is limited to children and women only as these two sub-sections of the population are most affected by anaemia [17, 18]. Very limited research is available examining anaemia among men in India and across various countries $[19,20]$. Most of the studies examining anaemia among men in India are community-based [21, 22]. The limited literature on anaemia among men prompted us to include men in our study. Previously a few studies have examined the prevalence and etiology of anaemia among women, men, and children [19]. However, this study took a different approach and examined the triple burden of anaemia in the same household. To the best of our knowledge, this is the first study to examine the co-existence of the triple burden of anaemia among mother-father-child pairs in India.

\section{Methods}

The study used a nationally representative fourth round of National Family Health Survey data, conducted in
2015-16 under the stewardship of the Ministry of Health and Family Welfare (MoHFW), Government of India. The survey provides information on population, health, and demographic aspects of households, men, women, and children for India as a whole, as well as for each state (29) and union territory (7) and district (640). A total of 601, 509 households, 699,686 eligible women aged $15-49$ years, and 112,122 men aged 15-54 years were interviewed with a response rate of $98 \%, 97 \%$, and $92 \%$, respectively. The detailed methodology, with complete information on the survey design and data collection, was published elsewhere [23]. The study excluded currently pregnant women's sample from the analysis as the cut-off of anaemia for pregnant and non-pregnant women is different. The effective sample size for the study was 26,910 couples, along with children aged 6-59 months.

\section{Outcome variable}

The outcome variable of the study was created with the combination of three dichotomous variables, namely, mother's anaemia level (anaemic and not anaemic), father's anaemia level (anaemic and not anaemic) and child's anaemia level (anaemic and not anaemic). For the study purpose, a dichotomous variable was generated with the help of the above-mentioned variables. If the couple was anaemic along with the child, it was coded as one means "anaemic", and if the couple was not anaemic along with the child, it was coded as 0 means "not anaemic". Women's blood haemoglobin level categorized as anaemic $(<12 \mathrm{~g} / \mathrm{dl})$ and not anaemic $(\geq 12 \mathrm{~g} / \mathrm{dl})$, men's blood haemoglobin level divided as anaemic $(<13 \mathrm{~g} / \mathrm{dl})$ and not anaemic $(\geq 13 \mathrm{~g} / \mathrm{dl})$ [24]. Also, the study used children anaemia level, and categorized them as anaemic $(<11 \mathrm{~g} / \mathrm{dl})$ and not anaemic $(\geq 11 \mathrm{~g} / \mathrm{dl})$ [25]. The outcome variable of the study was created with the combination of three dichotomous variables, namely, mother's anaemia level (anaemic and not anaemic), father's anaemia level (anaemic and not anaemic) and child's anaemia level (anaemic and not anaemic) [23].

\section{Exposure variables}

The study included couple's age, couple's education, couple's employment status, caste, religion, wealth quintile, and regions as exposure variables. 'Couple's age was categorized as: both young (15-24 or $<25$ years), both old ( $\geq 25$ years), and others). Couple's education was categorized as: both uneducated, both educated, and anyone educated. The working status of couples was grouped as: both unemployed, both working, and anyone working. Caste was divided into four categories: Scheduled Caste (SC), Scheduled Tribe (ST), Other Backward Caste (OBC), and others [26]. Religion was categorized as Hindu, Muslim, and others (including Christian, Sikh, Buddhist/Neo-Buddhist, Jain, Jewish, Parsi/Zoroastrian, 
no religion, and others). Wealth quintile was calculated by combining household's amenities, assets, and durables and characteristics households in a range varying from lowest to the highest in a five-point Likert scale [27]. Place of residence was given as urban and rural. Geographical regions were categorized as North, Central, East, Northeast, West, and South [28].

\section{Statistical analysis}

The bivariate and binary logistic regression analyses were applied to assess the factors associated with familylevel anaemia. In bivariate analysis, a chi-square test was performed to determine the association of sociodemographic factors with anaemic family [29]. The adjusted odds ratio with a 95\% confidence interval was presented in results.

The equation form of the model as follows:

$$
\ln \left(\frac{P_{i}}{1-P_{i}}\right)=\beta_{0}+\beta_{1} x_{1}+\cdots+\beta_{M^{x_{m-1}}}
$$

Where $\beta_{0}, \ldots ., \beta_{M}$ are regression coefficient indicating the relative effect of a particular explanatory variable on the family anaemia. These coefficients change as per the context in the analysis in the study [30].

\section{Results}

Table 1 represents the socio-demographic profile of the study population in India. It was found that $7 \%$ of couples were young, i.e., in the age group of less than 25 years. About $12.2 \%$ of couples were uneducated, whereas $20.5 \%$ of couples include anyone educated among them. Nearly $23.7 \%$ of couples belong to other caste categories, and about $80 \%$ of couples belong to the Hindu religion. Surprisingly, about $44 \%$ of a couple belongs from poor wealth quintiles, which include the poorest and poorer categories. Nearly $69 \%$ of couples belong to rural areas, and $25 \%$ of couples belong to central India.

Figure 1 reveals that almost $5 \%$ of all family members were suffering from anaemia in India, which includes mother (57.5\%), father (9.9\%), and child (58\%) as anaemic.

Table 2 reveals the percentage distribution of familylevel anaemia (mother, father, and children) by background characteristics in India. The couple age difference was not found to be a significant factor for anaemia prevalence in a family. Nearly $7 \%$ of family anaemia was found if both mother and father were uneducated. Interestingly, anaemia prevalence was high $(5.8 \%)$ in a family if both couples were employed. Anaemia prevalence was high in the family, which belongs to the Scheduled Tribe caste $(8.3 \%)$. Families form the Hindu religion was having a higher prevalence of anaemia (4.8\%). Families from Poor wealth status (6.4\%) and rural areas (5.4\%) were
Table 1 Socio-demographic profile of the study population, India, 2015-16

\begin{tabular}{|c|c|c|}
\hline Background variables & Percentage & Sample \\
\hline \multicolumn{3}{|l|}{ Couple's age } \\
\hline Both young & 7.0 & 1849 \\
\hline Both old & 67.4 & 19,014 \\
\hline Others & 25.7 & 6047 \\
\hline \multicolumn{3}{|l|}{ Couple's education } \\
\hline Both uneducated & 12.2 & 3517 \\
\hline Both educated & 67.3 & 17,595 \\
\hline Anyone educated & 20.5 & 5798 \\
\hline \multicolumn{3}{|l|}{ Couple's employment } \\
\hline Both unemployed & 7.0 & 1949 \\
\hline Both employed & 16.7 & 4618 \\
\hline Anyone employed & 76.2 & 20,343 \\
\hline \multicolumn{3}{|l|}{ Caste } \\
\hline Scheduled Caste & 20.6 & 5034 \\
\hline Scheduled Tribe & 11.0 & 5625 \\
\hline Other Backward Class & 44.6 & 10,260 \\
\hline Others & 23.7 & 5991 \\
\hline \multicolumn{3}{|l|}{ Religion } \\
\hline Hindu & 79.7 & 19,495 \\
\hline Muslim & 15.5 & 4246 \\
\hline Others & 4.7 & 3169 \\
\hline \multicolumn{3}{|l|}{ Wealth quintile } \\
\hline Poor & 43.8 & 12,735 \\
\hline Middle & 21.2 & 5613 \\
\hline Rich & 35.0 & 8562 \\
\hline \multicolumn{3}{|l|}{ Place of residence } \\
\hline Urban & 31.0 & 6954 \\
\hline Rural & 69.0 & 19,956 \\
\hline \multicolumn{3}{|l|}{ Region } \\
\hline North & 13.4 & 5446 \\
\hline Central & 25.1 & 7339 \\
\hline East & 21.9 & 4843 \\
\hline Northeast & 3.5 & 3747 \\
\hline West & 15.7 & 2483 \\
\hline South & 20.4 & 3052 \\
\hline
\end{tabular}

having a higher prevalence of anaemia. Families from the eastern part of India had the highest prevalence of anaemia (6.9\%).

Table 3 presents the logistic regression estimates for anaemic families by background characteristics in India. It was found that if couples, i.e., mother and father, both were educated, then the likelihood of anaemia in a family was low [OR: 0.69, CI: 0.58-0.81]. Additionally, if the mother or father, i.e., anyone among them, was 


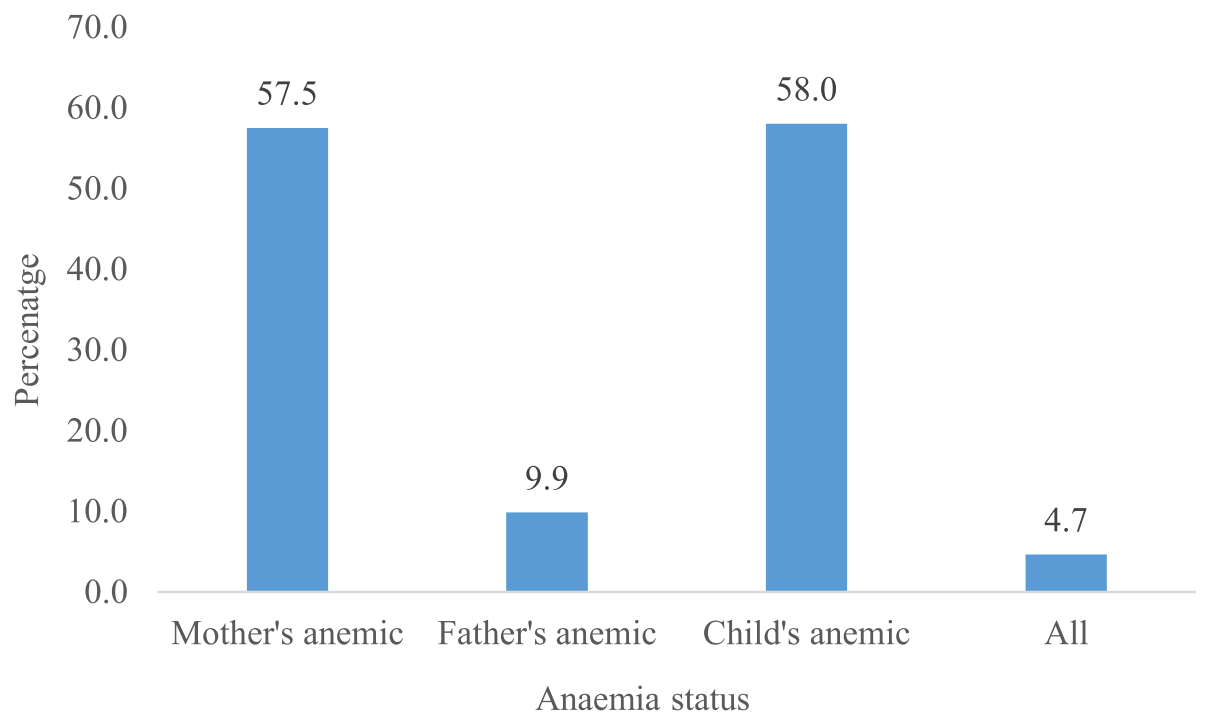

Fig. 1 Percentage of anaemia among family members in India, 2015-16

educated, then the likelihood of anaemia in a family was low [OR: 0.82, CI: 0.0.70-0.97]. If both mother and father were employed, then the odds of anaemia in the family was high [OR: 1.40 CI: 1.10-1.80]. Families from the Scheduled Tribe had a $62 \%$ higher likelihood to suffer from anaemia [OR: 1.62, CI: 1.33-1.97]. Families from the rich wealth quintile were $44 \%$ less likely to suffer from anaemia than families from the poor wealth quintile [OR: 0.56, CI: 0.47-0.68]. Families from the eastern part of India were 9\% more likely to suffer from anaemia than families in the northern part of India; however, the results were not significant [OR: 1.09, CI: 0.91-1.30]. Moreover, families from north-east India had a lower likelihood to suffer from anaemia than families from north India [OR: 0.36, CI: 0.28-0.47]. Moreover, the similar findings were found for other regions including central region [OR: 0.86, CI: 0.73-1.02], Western region [OR: $0.53, \mathrm{CI}: 0.41-0.69]$ and Southern region [OR: 0.72, CI: $0.57-0.91]$.

\section{Discussion}

The main objective of the study was to examine the triple burden of anaemia in the same household where the focus was on the mother, father, and their last-born child. Result found that around $4.7 \%$ of households suffer from the triple burden of anaemia. Previously, various studies have examined the anaemia in mother-child pairs [31]; however, there is a scarcity of literature examining anaemia in mother-father-child pairs in the same household. We have examined the co-existence of anaemia among mother-father-child pairs at the household level. The study found that more than half of the mothers $(57.5 \%)$ and children (58\%) were anaemic. In contrast, only $10 \%$ of fathers were anaemic. The prevalence of anaemia among mothers and children, as found in this study, is higher than the prevalence of anaemia in mothers and children in Nepal and lower than in Pakistan [32]. The prevalence of anaemia among children in Bangladesh was lower than in India, as found in this study [33]. This study illustrated that around $5 \%$ of the mother-father-child pairs were anaemic in the same household. The co-existence of anaemia among motherfather-child pairs was found to be lower when both the parents were educated and the household belonged to rich wealth quintiles. In contrast, the co-existence of anaemia among mother-father-child pairs was higher when both the parents were employed and the household belonged to Scheduled Tribe.

This study has confirmed that with an increase in couple's education, the triple burden of anaemia among mother-father-child pair's decreases significantly. Previously, researchers have unanimously agreed in concluding that increasing the level of education has a negative association with anaemia $[9,34]$. Child's anaemia levels are widely affected by the mother's level of education [9, 35]. Maternal education has found to be associated with an increased knowledge of healthcare and nutrition, which may possibly be linked to a reduction in anaemia level among members residing in a family [35]. Moreover, for child feeding practices, the mother's education level is believed to be the key factor as mothers are the primary caregivers [36]. Further, it has been highlighted that likelihood of anaemia among children is higher when the anaemia levels are high among mothers [37, 38]. Therefore, it is understood that if a mother is anaemic, then the probability of a child being anaemic is high. Furthermore, severe anaemia among mothers may also impact the iron content in breast milk, which may 
Table 2 Percent distribution of family-level anaemia (mother, father, and children) by background characteristics, India, 2015-16

\begin{tabular}{|c|c|c|c|}
\hline Background variables & Anaemia (\%) & Confidence Interval (Cl) & $p$-value \\
\hline Couple's age & & & 0.838 \\
\hline Both young & 5.0 & $(4.07-6.07)$ & \\
\hline Both old & 4.5 & $(4.17-4.76)$ & \\
\hline Others & 5.1 & $(4.59-5.70)$ & \\
\hline Couple's education & & & 0.001 \\
\hline Both uneducated & 7.1 & $(6.28-7.98)$ & \\
\hline Both educated & 3.8 & $(3.58-4.15)$ & \\
\hline Anyone educated & 5.9 & $(5.27-6.48)$ & \\
\hline Couple's employment & & & 0.002 \\
\hline Both unemployed & 4.6 & $(3.76-5.63)$ & \\
\hline Both employed & 5.8 & $(5.10-6.45)$ & \\
\hline Anyone employed & 4.4 & $(4.16-4.72)$ & \\
\hline Caste & & & 0.001 \\
\hline Scheduled Caste & 4.3 & $(3.77-4.89)$ & \\
\hline Scheduled Tribe & 8.3 & $(7.58-9.03)$ & \\
\hline Other Backward Class & 4.7 & $(4.23-5.04)$ & \\
\hline Others & 3.3 & $(2.90-3.81)$ & \\
\hline Religion & & & 0.094 \\
\hline Hindu & 4.8 & $(4.56-5.17)$ & \\
\hline Muslim & 3.8 & $(3.23-4.38)$ & \\
\hline Others & 4.5 & $(3.74-5.18)$ & \\
\hline Wealth quintile & & & 0.001 \\
\hline Poor & 6.4 & $(5.99-6.84)$ & \\
\hline Middle & 4.2 & $(3.75-4.81)$ & \\
\hline Rich & 2.7 & $(2.37-3.06)$ & \\
\hline Place of residence & & & 0.001 \\
\hline Urban & 3.1 & $(2.69-3.50)$ & \\
\hline Rural & 5.4 & $(5.06-5.68)$ & \\
\hline Region & & & 0.001 \\
\hline North & 4.1 & $(3.63-4.69)$ & \\
\hline Central & 4.9 & $(4.38-5.37)$ & \\
\hline East & 6.9 & $(6.24-7.67)$ & \\
\hline Northeast & 4.2 & $(3.55-4.84)$ & \\
\hline West & 3.1 & $(2.50-3.88)$ & \\
\hline South & 3.6 & $(2.87-4.18)$ & \\
\hline
\end{tabular}

\%: Percentage; Cl Confidence interval

lead to nutritional deficiency in the child and may aggravate anaemia among children [9]. A few studies have noticed a low level of anaemia among children with a higher father's education level [39]; however, the pathways through which father's education improves anaemia in their children are largely unexplored. One possible pathway suggests that educated parents may have a higher income, which may further have a bearing on improving a child's nutrition and feeding practices [40].
Another important finding from this study highlighted that the triple burden of anaemia was higher when both the parents were employed as in comparison to when both the parents were unemployed. However, previous findings have concluded that the unemployment of either parent is positively associated with anaemia levels [41]. In relation to unemployment and anaemia, it can be understood that that unemployment among parents may lead to poor socio-economic status, which may 
Table 3 Estimates from binary logistic regression analysis for the anaemic family by background characteristics, India, 201516

\begin{tabular}{|c|c|}
\hline Background variables & OR $[95 \% \mathrm{Cl}]$ \\
\hline \multicolumn{2}{|l|}{ Couple's age } \\
\hline Both young & Ref. \\
\hline Both old & $1.00(0.80-1.25)$ \\
\hline Others & $1.12(0.88-1.42)$ \\
\hline \multicolumn{2}{|l|}{ Couple's education } \\
\hline Both uneducated & Ref. \\
\hline Both educated & $0.69^{* * *}(0.58-0.81)$ \\
\hline Anyone educated & $0.82^{* *}(0.70-0.97)$ \\
\hline \multicolumn{2}{|l|}{ Couple's employment } \\
\hline Both unemployed & Ref. \\
\hline Both employed & $1.40^{* * *}(1.10-1.80)$ \\
\hline Anyone employed & $1.20(0.96-1.50)$ \\
\hline \multicolumn{2}{|l|}{ Caste } \\
\hline Scheduled Caste & $0.92(0.75-1.13)$ \\
\hline Scheduled Tribe & $1.62^{* * *}(1.33-1.97)$ \\
\hline Other Backward Class & $1.09(0.92-1.30)$ \\
\hline Others & Ref. \\
\hline \multicolumn{2}{|l|}{ Religion } \\
\hline Hindu & Ref. \\
\hline Muslim & 0.93(0.78-1.10) \\
\hline Others & $1.17(0.93-1.48)$ \\
\hline \multicolumn{2}{|l|}{ Wealth quintile } \\
\hline Poor & Ref. \\
\hline Middle & $0.83^{* *}(0.71-0.97)$ \\
\hline Rich & $0.56^{* * *}(0.47-0.68)$ \\
\hline \multicolumn{2}{|l|}{ Place of residence } \\
\hline Urban & Ref. \\
\hline Rural & 1.05(0.90-1.23) \\
\hline \multicolumn{2}{|l|}{ Region } \\
\hline North & Ref. \\
\hline Central & $0.86^{*}(0.73-1.02)$ \\
\hline East & $1.09(0.91-1.30)$ \\
\hline Northeast & $0.36^{* * *}(0.28-0.47)$ \\
\hline West & $0.53^{* * *}(0.41-0.69)$ \\
\hline South & $0.72^{* * *}(0.57-0.91)$ \\
\hline
\end{tabular}

worsen the nutritional intake and healthcare utilization and, as a result, aggravate the risk of anaemia [41]. Studies have noticed that employed parents have higher income, which betters the nutritional intakes and further has a bearing on the improvements of the anaemia level [42-44]. Assefa, Mossie, \& Hamza (2014), in a community-based study, concluded that the problem of anaemia is linked with food insecurity, often characterized by economic constraints [43]. Moreover, some studies noticed no association between employment and anaemia [45]. However, in contrast to the previously available literature as discussed above, this study noticed a higher level of anaemia when both the parents were employed. The higher levels of anaemia when both the parents were employed may be attributed to the fact that when both the parents are working, they get less time in taking care of themselves along with their children and may fail in providing nutrition-rich foods. Employed parents find it tough to manage work-family conflict, and that may have an effect on child health, too [46].

Anaemia among mother-father-child pairs was higher among those who belonged to Scheduled Tribe. In the Indian context, Scheduled Tribes are socially and economically backward castes [47]. The tribal population was found to be at higher risk of under-nutrition because of their socio-economic conditions, and they also have poor health-seeking behavior [48]. Undernutrition among the tribal population is a well-known attribute of higher levels of anaemia among them [49]. Furthermore, the wealth quintile was found to be another predictor of anaemia among the study population. It was noticed that the triple burden of anaemia in a family decreases with an increase in their wealth. Previously, high levels of anaemia were found to be associated with the lowest wealth quintile $[6,50,51]$. Higher wealth in a household is directly linked to the higher nutritional purchasing parity [52]. The study concluded that the family-level anaemia burden was higher in the Northern region and lowered in the North-eastern, Western, and Southern regions of the country. A study has noticed a higher level of anaemia among children in the Northern region and lower levels of anaemia among children in Southern and North-eastern regions of India [52]. Jain \& Agnihotri (2020), while examining nutritional outcomes in children, highlighted that Southern states like Tamil Nadu and Kerala were able to maintain balanced development in improving levels of anaemia over time by implementing programs like Integrated Child Development Scheme (ICDS) and other health missions in a holistic way [53].

The study has a few limitations. The cross-sectional nature of data limits our understanding to draw causal inferences from the findings, and hence, we could not follow the direction of causality. We could not examine district-level differentials as data for men was only available at the state level; hence, we examined regional differences only. The HemoCue device was used to test the capillary blood sample instead of venous blood in a laboratory; this may lead to an underestimation of anaemia [54]. In contrast, a study claimed that HemoCue provides an accurate measurement of anaemia [13]. 
While examining the co-existence of anaemia among mother-father-child pairs, we only measured anaemia for the last born child and not for all the children born to the couple. Furthermore, there may be a few unmeasured variables associated with anaemia we could not capture due to data limitation. Despite the above limitation, this study has several strengths. To the best of our knowledge, this is the first study that examined the triple burden of anaemia in a family by combining motherfather-child pairs in India. This study utilized nationally representative data, and hence, findings can be generalized at the national level.

\section{Conclusion}

The study identified several risk factors that could be targeted to reduce the triple burden of anaemia among mother-father-child pairs in India. The limited availability of evidence in examining the triple burden of anaemia at the family level prompted us to suggest that there is a need to carry further studies in the related domain to conclude the findings evidently. The suggested interventions include early diagnosis, effective management, and treatment of anaemia. Moreover, adequate complementary feeding practices for children shall also be promoted. Parental education on nutrition is also required, and community interventions are needed to improve parental education on nutrition. Policy-makers may involve the local leaders or ASHA workers to disseminate nutrition education to the parents. At last, there is a need for greater policy and program attention to improving nutritional knowledge among mothers so as to tackle the triple burden of anaemia among motherfather-child pairs.

\section{Abbreviations}

NFHS: National Family Health Survey; OR: Odds Ratio; Cl: Confidence Interval; ST: Scheduled Tribe; SC: Scheduled Caste; OBC: Other Backward Class

\section{Acknowledgements}

Not applicable.

\section{Authors' contributions}

The concept was drafted by SS; PK and SS contributed to the analysis design, PK and SS advised on the paper and assisted in paper conceptualisation. RP and SC contributed in the comprehensive writing of the article. All authors read and approved the final manuscript.

\footnotetext{
Author's information

Pradeep Kumar completed his M.Phil. in Population studies and currently pursuing his PhD in Population studies from International Institute for Population Sciences, Mumbai, India. His area of interest is Ageing and reproductive health among married women in India.

Shekhar Chauhan has completed his M.A. in Population studies and currently pursuing his Ph.D. in Population studies from International Institute for Population Sciences, Mumbai, India. His area of interest is public health issues in India.

Ratna Patel completed her Masters in Population Studies and currently pursuing her Ph.D. in Population studies from International Institute for Population Sciences, Mumbai, India. Her area of interest is public health issues in India.
}

Shobhit Srivastava completed his M.Phil. in Population studies and currently pursuing his PhD in Population studies from International Institute for Population Sciences, Mumbai, India. His area of interest is Public health issues among adults in India.

\section{Funding}

Authors did not received any funding to carry out this research.

\section{Availability of data and materials}

The study utilises secondary source of data which is available on request and is available in public domain through.

(https://dhsprogram.com/data/dataset/India_Standard-DHS_2015.cfm?flag=0)

\section{Declarations}

\section{Ethics approval and consent to participate}

The data is freely available in public domain and survey agencies that conducted the field survey for the data collection have collected a prior consent from the respondent. Local ethics committee of International Institute for Population Sciences (IIPS), Mumbai, ruled that no formal ethics approval was required to carry out research from this data source.

\section{Consent for publication}

Not applicable.

\section{Competing interests}

The authors declare that they have no competing interests.

Received: 19 October 2020 Accepted: 28 June 2021

Published online: 07 July 2021

\section{References}

1. Cappellini MD, Musallam KM, Taher AT. Iron deficiency anaemia revisited. J Intern Med. 2020;287(2):153-70. https://doi.org/10.1111/joim.13004.

2. Barragán-Ibañez G, Santoyo-Sánchez A, Ramos-Peñafiel CO. Iron deficiency anaemia. Rev Médica del Hosp Gen México. 2016;79(2):88-97. https://doi. org/10.1016/j.hgmx.2015.06.008.

3. Lopez A, Cacoub P, Macdougall IC, et al. Iron deficiency anaemia. In: The Lancet: Lancet Publishing Group. p. 907-16.

4. Kumar P, Sharma H, Patel KK. Prevalence and risk factors of anaemia among men: a study based on empowered action group states, India. Nutr Health. 2021;(2):191-8. https://doi.org/10.1177/0260106020982348.

5. Didzun O, Jan-Walter De N, Awasthi A, Dubey M, Theilmann M, Bärnighausen T, et al. Anaemia among men in India: a nationally representative cross-sectional study. Lancet Global Health. 2019;7:E1685e1694. https://doi.org/10.1016/S2214-109X(19)30440-1.

6. Dutta $M$, Bhise $M$, Prashad $L$, et al. Prevalence and risk factors of anemia among children 6-59 months in India: A multilevel analysis. Clin Epidemiol Glob Heal. 2020. https://doi.org/10.1016/j.cegh.2020.02.015.

7. Pasricha SR, Black J, Muthayya S, Shet A, Bhat V, Nagaraj S, et al. Determinants of anemia among young children in rural India. Pediatrics. 2010;126(1):e140-9. https://doi.org/10.1542/peds.2009-3108.

8. Baranwal A, Baranwal A, Roy N. Association of household environment and prevalence of anemia among children under-5 in India. Front Public Heal. 2014. https://doi.org/10.3389/fpubh.2014.00196.

9. Onyeneho NG, Ozumba BC, Subramanian SV. Determinants of Childhood Anemia in India. Sci Rep. 2019;9(1):16540. https://doi.org/10.1038/s41598-01 9-52793-3.

10. Siddiqui MZ, Goli S, Reja T, et al. Prevalence of Anemia and Its Determinants Among Pregnant, Lactating, and Nonpregnant Nonlactating Women in India. SAGE Open. 2017. https://doi.org/10.1177/2158244017725555.

11. Sharma H, Singh SK, Srivastava S. Major Correlates of Anemia among Women (Age 15-49) in India and Spatial Variation, Evidence from National Family Health Survey-4. J Women's Heal Care. 2018. https://doi.org/10.41 72/2167-0420.1000440

12. Pant A, Scott S, Nguyen P, Yadav K, Menon P. Anemia Affects One in Four Indian Men and Has Not Decreased in the Last Decade: Trends, Geographic Variability and Predictors from Nationally Representative Data, 2005 to 2016. Curr Dev Nutr. 2020;(Supplement_2). https://doi. org/10.1093/cdn/nzaa067_057. 
13. Demirchyan A, Petrosyan V, Sargsyan V, et al. Prevalence and determinants of anaemia among children aged 0-59 months in a rural region of Armenia: A case-control study. Public Health Nutr. 2016. https://doi.org/10.1017/S13 68980015002451.

14. Singal N, Setia G, Taneja BK, Singal KK. Factors associated with maternal anaemia among pregnant women in rural India. Bangladesh J Med Sci. 2018;17(4):583-92. https://doi.org/10.3329/bjms.v17i4.38320.

15. Mangla M, Singla D. Prevalence of anaemia among pregnant women in rural India: a longitudinal observational study. Int J Reprod Contraception, Obstet Gynecol. 2016. https://doi.org/10.18203/2320-1770.ijrcog20163431.

16. Nguyen PH, Scott $S$, Avula $R$, Tran LM, Menon P. Trends and drivers of change in the prevalence of anaemia among 1 million women and children in India, 2006 to 2016. BMJ Glob Heal. 2018;(5):e001010. https://doi.org/1 0.1136/bmjgh-2018-001010.

17. Moschovis PP, Wiens MO, Arlington L, et al. Individual, maternal and household risk factors for anaemia among young children in sub-Saharan Africa: A cross-sectional study. BMJ Open. 2018. https://doi.org/10.1136/ bmjopen-2017-019654

18. Ahmed F, Prendiville N, Narayan A. Micronutrient deficiencies among children and women in Bangladesh: Progress and challenges. J Nutr Sci. 2016:5:e46. https://doi.org/10.1017/jns.2016.39.

19. Tadesse AW, Hemler EC, Andersen C, et al. Anemia prevalence and etiology among women, men, and children in Ethiopia: A study protocol for a national population-based survey. BMC Public Health. 2019. https://doi.org/1 0.1186/s12889-019-7647-7.

20. Didzun O, De Neve JW, Awasthi A, et al. Anaemia among men in India: a nationally representative cross-sectional study. Lancet Glob Heal. 2019;(12): e1685-94. https://doi.org/10.1016/S2214-109X(19)30440-1.

21. Kant S, Kumar R, Malhotra S, et al. Prevalence and determinants of anemia among adult males in a rural area of Haryana, India. J Epidemiol Glob Health. 2019. https://doi.org/10.2991/jegh.k.190513.001.

22. Little M, Zivot C, Humphries S, Dodd W, Patel K, Dewey C. Burden and determinants of anemia in a rural population in South India: A crosssectional study. Anemia. 2018;2018:1-9. https://doi.org/10.1155/2018/7123 976.

23. International Institute for Population Sciences (IIPS) and ICF. National Family Health Survey (NFHS-4); 2017. p. 199-249.

24. Goddard AF, James MW, McIntyre AS, et al. Guidelines for the management of iron deficiency anaemia. Gut. 2011;60(10):1309-16. https://doi.org/10.113 6/gut.2010.228874

25. Sharma H, Singh SK, Srivastava S. Socio-economic inequality and spatial heterogeneity in anaemia among children in India: Evidence from NFHS-4 (2015-16). Clin Epidemiol Glob Heal. 2020. https://doi.org/10.1016/j.cegh.202 0.04.009.

26. Srivastava $\mathrm{S}$, Kumar S. Does socio-economic inequality exist in micronutrients supplementation among children aged 6-59 months in India? Evid Natl Fam Health. 2021:21:1-12.

27. Singh SK, Srivastava S, Chauhan S. Inequality in child undernutrition among urban population in India: a decomposition analysis. BMC Public Health. 2020;20(1):1852. https://doi.org/10.1186/s12889-020-09864-2.

28. Kumar P, Patel R, Chauhan $\mathrm{S}$, et al. Does socio-economic inequality in infant mortality still exists in India? An analysis based on National Family Health Survey 2005-06 and 2015-16. Clin Epidemiol Glob Heal. 2020;9:116-22.

29. McHugh ML. The Chi-square test of independence. Biochem Medica. 2012. https://doi.org/10.11613/BM.2013.018.

30. Osborne J, King JE. Binary logistic regression. In: Best Practices in Quantitative Methods: SAGE Publications, Inc; 2011. p. 358-84.

31. Khan JR, Islam MM, Biswas RK, Sultana A. An assessment of anemia status of child-mother pairs in Bangladesh. Child Youth Serv Rev. 2020;112:104851. https://doi.org/10.1016/j.childyouth.2020.104851.

32. Harding KL, Aguayo VM, Namirembe G, Webb P. Determinants of anemia among women and children in Nepal and Pakistan: An analysis of recent national survey data. Matern Child Nutr. 2018;14(S4). https://doi.org/10.1111/ men.12478.

33. Khan JR, Awan N, Misu F. Determinants of anemia among 6-59 months aged children in Bangladesh: Evidence from nationally representative data. BMC Pediatr. 2016. https://doi.org/10.1186/s12887-015-0536-z.

34. Kuziga F, Adoke Y, Wanyenze RK. Prevalence and factors associated with anaemia among children aged 6 to 59 months in Namutumba district, Uganda: A cross- sectional study. BMC Pediatr. 2017. https://doi.org/10.1186/ s12887-017-0782-3.
35. Ojoniyi OO, Odimegwu CO, Olamijuwon EO, et al. Does education offset the effect of maternal disadvantage on childhood anaemia in Tanzania? Evidence from a nationally representative cross-sectional study. BMC Pediatr. 2019. https://doi.org/10.1186/s12887-019-1465-z.

36. Huang Z, Jiang FX, Li J, et al. Prevalence and risk factors of anemia among children aged 6-23 months in Huaihua, Hunan Province. BMC Public Health. 2018. https://doi.org/10.1186/s12889-018-6207-x.

37. Mya KS, Kyaw AT, Tun T. Feeding practices and nutritional status of children age 6-23 months in Myanmar: A secondary analysis of the 2015-16 Demographic and Health Survey. PLoS One. 2019. https://doi.org/10.1371/ journal.pone.0209044.

38. Torlesse H, Aguayo VM. Aiming higher for maternal and child nutrition in South Asia. Mater Child Nutr. 2018;14(S4). https://doi.org/10.1111/ mcn.12739.

39. Khanal $V$, Karkee $R$, Adhikari $M$, et al. Moderate-to-severe anaemia among children aged 6-59 months in Nepal: An analysis from Nepal Demographic and Health Survey, 2011. Clin Epidemiol Glob Heal. 2016;(2):57-62. https:// doi.org/10.1016/j.cegh.2015.07.001.

40. Xin QQ, Chen BW, Yin DL, et al. Prevalence of anemia and its risk factors among children under 36 months old in China. J Trop Pediatr. 2017. https:// doi.org/10.1093/tropej/fmw049.

41. Simbauranga $\mathrm{RH}$, Kamugisha $\mathrm{E}$, Hokororo A, et al. Prevalence and factors associated with severe anaemia amongst under-five children hospitalized at Bugando medical Centre, Mwanza, Tanzania. BMC Hematol. 2015. https:// doi.org/10.1186/s12878-015-0033-5.

42. Muchie KF. Determinants of severity levels of anemia among children aged 6-59 months in Ethiopia: further analysis of the 2011 Ethiopian demographic and health survey. BMC Nutr. 2016;(1). https://doi.org/10.1186/ s40795-016-0093-3.

43. Assefa S, Mossie A, Hamza L. Prevalence and severity of anemia among school children in Jimma Town, Southwest Ethiopia. BMC Hematol. 2014. https://doi.org/10.1186/2052-1839-14-3

44. Cotta RMM, de Cássia Carvalho Oliveira F, Magalhães KA, et al. Social and biological determinants of iron deficiency anemia. Cad Saude Publica. 2011. https://doi.org/10.1590/s0102-311×2011001400017.

45. Win HH, Ko MK. Geographical disparities and determinants of anaemia among women of reproductive age in Myanmar: analysis of the 2015-2016 Myanmar demographic and health survey. WHO South-East Asia J public Heal. 2018;(2):107-13. https://doi.org/10.4103/2224-3151.239422.

46. Kish AM, Newcombe PA, Haslam DM. Working and caring for a child with chronic illness: A review of current literature. Child Care Health Dev. 2018; 44(3):343-54. https://doi.org/10.1111/cch.12546.

47. Kumari J, Dubey R, Bose DK, et al. A study on socio- economic condition of Tharu tribes in Bahraich district of Uttar Pradesh in India. J Appl Nat Sci. 2018. https://doi.org/10.31018/jans.v10i3.1785.

48. Dey U, Bisai S. The prevalence of under-nutrition among the tribal children in India: a systematic review. Anthropol Rev. 2019;82(2):203-17. https://doi. org/10.2478/anre-2019-0015

49. Kulkarni R, Surve S, Patil S, et al. Nutritional status of adolescent girls in tribal blocks of Maharashtra. Indian J Community Med. 2019. https://doi.org/10.41 03/ijcm.IJCM_369_18.

50. Ntenda PAM, Nkoka O, Bass $P$, et al. Maternal anemia is a potential risk factor for anemia in children aged 6-59 months in Southern Africa: A multilevel analysis. BMC Public Health. 2018. https://doi.org/10.1186/s12889-018-5568-5.

51. Kothari MT, Coile A, Huestis A, et al. Exploring associations between water, sanitation, and anemia through 47 nationally representative demographic and health surveys. Ann N Y Acad Sci. 2019. https://doi.org/10.1111/nyas.14109.

52. Masood M, Reidpath DD. Effect of national wealth on BMI: An analysis of 206,266 individuals in 70 low-, middle-and high-income countries. PLoS One. 2017. https://doi.org/10.1371/journal.pone.0178928.

53. Jain A, Agnihotri SB. Assessing inequalities and regional disparities in child nutrition outcomes in India using MANUSH - a more sensitive yardstick. Int J Equity Health. 2020. https://doi.org/10.21203/rs.2.23291/v1.

54. Srivastava S, Chaurasia H, Kumar Singh KJ, et al. Exploring the spatial patterns of cesarean section delivery in India: Evidence from National Family Health Survey-4. Clin Epidemiol Glob Heal. 2019. https://doi.org/10.1016/j. cegh.2019.09.012.

\section{Publisher's Note}

Springer Nature remains neutral with regard to jurisdictional claims in published maps and institutional affiliations. 